\title{
Investigating neutrophil cell death in TB pathogenesis
}

\section{[version 1; peer review: 2 approved]}

\author{
Kimone L Fisher (D1,2, Kerishka Rajkumar-Bhugeloo1, Denelle Moodley", \\ Thabo Mpotje1, Duran Ramsuran1, Thumbi Ndung' 'u' ${ }^{1-4}$, \\ Mohlopheni J Marakalala (DiD)-3
}

\footnotetext{
${ }^{1}$ Africa Health Research Institute, Durban, KwaZulu-Natal, 4001, South Africa

${ }^{2}$ School of Laboratory Medicine and Medical Sciences, University of KwaZulu Natal, Durban, KwaZulu-Natal, 4001, South Africa

${ }^{3}$ Division of Infection and Immunity, University College London, London, UK

${ }^{4}$ HIV Pathogenesis Programme, Doris Duke Medical Research Institute, University of KwaZulu Natal, Durban, KwaZulu-Natal, 4001, South Africa
}

V1 First published: 07 Dec 2021, 5:175

https://doi.org/10.12688/gatesopenres.13472.1

Latest published: 29 Apr 2022, 5:175

https://doi.org/10.12688/gatesopenres.13472.2

\section{Abstract}

Background: Neutrophils are one of the major early role players in antimycobacterial immunity. Upon infection, neutrophils can undergo NETosis, a cell death characterized by release of neutrophil extracellular traps (NETs). The role of NETosis in TB progression remains poorly characterized. We aim to characterize mechanisms underlying NETosis during TB pathogenesis by identifying genes that drive the cell death, and to determine their potential as markers of disease progression in high-risk individuals. Finally, we intend to evaluate neutrophil associated genes as targets for host directed therapy to reduce pathological damage caused by NETosis. Methods: Quantitative PCR will be used to quantify expression of specific genes identified in the blood of individuals with active lung disease $(n=30)$, compared to those from healthy $(n=30)$ and latently infected individuals (LTBI) $(n=30)$. In addition, temporal events associated with NETosis will be measured using live microscopy in a neutrophil in vitro model of Mycobacterium tuberculosis (Mtb) infection. Candidate genes found to be associated with NETosis will be targeted with pharmaceutical inhibitors. Conclusion: Genes associated with neutrophil mediated cell death may serve as potential biomarkers of pathological damage and disease progression, as well as targets for host-directed therapy.

Keywords

Neutrophils, Tuberculosis, NETosis

\section{Open Peer Review \\ Approval Status \\ 1 2 \\ version 2 \\ (revision) \\ 29 Apr 2022 \\ version 1 \\ 07 Dec 2021

 \\ $\checkmark$ \\ 1. Ashwani Kumar ID, Institute of Microbial \\ Technology, Chandigarh, Chandigarh, India \\ 2. Delia Goletti iD), National Institute for \\ Infectious Diseases (INMI), Rome, Italy \\ Any reports and responses or comments on the article can be found at the end of the article.}


Corresponding author: Mohlopheni J Marakalala (mohlopheni.marakalala@ahri.org)

Author roles: Fisher KL: Data Curation, Formal Analysis, Investigation, Methodology, Visualization, Writing - Original Draft Preparation, Writing - Review \& Editing; Rajkumar-Bhugeloo K: Investigation, Methodology, Writing - Review \& Editing; Moodley D: Investigation, Methodology, Writing - Review \& Editing; Mpotje T: Investigation, Methodology, Writing - Review \& Editing; Ramsuran D: Data Curation, Visualization, Writing - Review \& Editing; Ndung'u T: Resources, Supervision, Writing - Review \& Editing; Marakalala MJ: Conceptualization, Formal Analysis, Funding Acquisition, Investigation, Methodology, Resources, Supervision, Writing - Original Draft Preparation, Writing - Review \& Editing

Competing interests: No competing interests were disclosed.

Grant information: MJM was funded by Grand Challenges, an initiative of the Bill \& Melinda Gates Foundation (grant \#OPP1210776, grant\# INV-016239) and the Wellcome Trust (grant\#206751/A/17/Z). The work reported herein was made possible through funding by the South African Medical Research Council through its Division of Research Capacity Development under the Internship Scholarship Programme (KLF) and Mid-Career Scientist Programme (MJM) from funding received from the South African National Treasury. The content hereof is the sole responsibility of the authors and does not necessarily represent the official views of the funders. The funders had no role in study design, data collection and analysis, decision to publish, or preparation of the manuscript.

Copyright: (c) 2021 Fisher KL et al. This is an open access article distributed under the terms of the Creative Commons Attribution License , which permits unrestricted use, distribution, and reproduction in any medium, provided the original work is properly cited.

How to cite this article: Fisher $\mathrm{KL}$, Rajkumar-Bhugeloo $\mathrm{K}$, Moodley $\mathrm{D}$ et al. Investigating neutrophil cell death in TB pathogenesis [version 1; peer review: 2 approved] Gates Open Research 2021, 5:175 https://doi.org/10.12688/gatesopenres.13472.1

First published: 07 Dec 2021, 5:175 https://doi.org/10.12688/gatesopenres.13472.1 


\section{Background}

Tuberculosis, caused by Mycobacterium tuberculosis (Mtb), is responsible for approximately 1.5 million deaths annually ${ }^{1}$. Understanding lung immunity during TB progression is important for the identification of disease biomarkers. During initial TB infection, an immune structure known as a granuloma, forms to control and prevent the spread of $\mathrm{Mtb}^{2}$. The granuloma is a highly organized immune structure composed of macrophages surrounded by a layer of epithelioid cells and multinucleated giant cells, with a lymphocytic cuff at the periphery $^{3}$. Neutrophils are also found in regions adjacent to caseum or necrotic regions of the granuloma ${ }^{4}$. Understanding the contribution of neutrophils to lung associated tissue damage is important to determine mechanisms that lead to TB associated pathology. Neutrophils are the most abundant immune cell subsets in the lung and are among the first cells that are infected with $\mathrm{Mtb}^{5}$. Neutrophils play an important role in bacterial control during acute infection, however, they can release reactive oxygen species (ROS), DNA, myeloperoxidase, cathelicidins and S100 proteins that can result in excessive inflammation and damage to surrounding tissue $e^{6,7}$. NETosis is the release of nuclear DNA and associated proteins i.e histones, called neutrophil extracellular traps (NETS) from the cell in response to bacterial, viral or stress induced conditions ${ }^{8}$. The size of the NETS released is dependent on the size of the pathogen ${ }^{9}$, which is important in combatting infection. However, NETosis has also been shown to contribute to tissue damage in various diseases $^{10-12}$. Studying neutrophils in a clinically relevant environment is challenging due to their short life-span and the various complex triggers of activation, including respiratory stress, damage-signalling or prior activation to pathogenic stimuli resulting in ROS associated activities ${ }^{13}$.

Neutrophilia, which is a characterized by an abundance of neutrophils above what is considered to be a normal count, has been associated with TB and it is therefore important to understand mechanisms underlying neutrophil mediated contribution to disease pathogenesis ${ }^{14,15}$. In previous findings, we reported that across cellular, caseous and cavitary granulomas, proteins associated with neutrophils were abundant in necrotic regions ${ }^{16}$. Other studies have also reported presence of neutrophils around caseous regions ${ }^{4}$ and in the border of necrotizing tissue ${ }^{6}$. However, whether neutrophils are directly causing caseation and how it is mediated remains a gap in our knowledge. Our project is therefore aimed at determining expression profiles of neutrophil associated genes in blood from healthy, LTBI and TB participants as potential markers of the disease. We also intend to investigate the role of neutrophils during TB pathogenesis by exploring, in-vitro, the dynamics of NETosis, in neutrophils infected with Mtb and to target drivers of the cell death as host directed therapies (HDT).

\section{Methods}

\section{Study design and setting}

This is a prospective study that includes participants recruited from healthcare facilities that service the eThekwini
District in KwaZulu-Natal (KZN), South Africa. Participants were recruited from Kwadabeka Clinic and Prince Zulu Communicable Disease Centre in Durban. South Africa has a TB prevalence rate of 737 in 100000 in $2017^{17}$ with eThekwini described as having the highest TB prevalence rate in KZN. This study was approved by the Biomedical Research Ethics Committee (BREC) at the University of KwaZulu-Natal (BE022/13 and BE00003365/21).

\section{Study size and ethics}

A qualified nurse will enrol participants into the study after explaining the informed consent procedure according to good clinical health practices (Figure 1). Written consent will be obtained from all participants or their legal guardians. Participants will be incentivised for participating in the study according to the ethics that have been approved through the University of KwaZulu-Natal. Participants are informed that their biological samples will be stored for future use, including their genetic information, which will be used for research. A volume of twenty millilitres of blood will be used for neutrophil isolation. Plasma is collected and stored at $-80^{\circ} \mathrm{C}$ (Figure 2). Approximately thirty participants will be recruited per group.

\section{Sample processing}

Samples that are obtained will be assigned a unique participant identification (PID). A maximum volume of forty millilitres of blood will be drawn from each participant. Two and a half millilitres of blood will be stored for PAXgene processing in order to isolate ribonucleic acid (RNA) for genetic studies. PAXgene tubes are stored at $-20^{\circ} \mathrm{C}$ overnight at angle and transferred to the $-80{ }^{\circ} \mathrm{C}$ freezer the following day until processing as per the manufacturer's instructions (Figure 2). Twenty millilitres of blood will be collected and used to isolate peripheral blood mononuclear cells (PBMCs) or neutrophils and the remaining ten millilitres of blood will be used to collect plasma.

\section{Neutrophil isolation}

A volume of blood ranging between ten and twenty millilitres of blood will be collected in heparin collection tubes (Figure 2). The blood will be transferred to $50 \mathrm{ml}$ conical tubes. A volume of ten millilitres of $0.01 \mathrm{M}$ phosphate buffered solution (PBS) will be added to the blood collection tubes, to remove any blood remnants and then added to the $50 \mathrm{ml}$ conical tube. A volume of twelve millilitres of the Cell-based Assay Neutrophil Isolation Histopaque (Sigma-Aldrich, Germany) will be placed in a new conical tube at room temperature (RT). The diluted blood will be pipetted on top of the histopaque and centrifuged at $800 \times \mathrm{g}$ for 20 minutes at RT, with the centrifuge setting of acceleration slow and deceleration off. The yellow and clear upper layers will be aspirated, leaving only the red blood cell (RBC) layer and neutrophils. A volume of twenty-five millilitres of the RBC lysis buffer ( $1 \mathrm{x}$ solution) will be added to the RBC and neutrophil layer and mixed. The mixture will be incubated at RT for 10 minutes. Following incubation, the cells will be centrifuged at $250 \mathrm{x} \mathrm{g}$ for 5 minutes at RT to pellet the neutrophils. The supernatant 


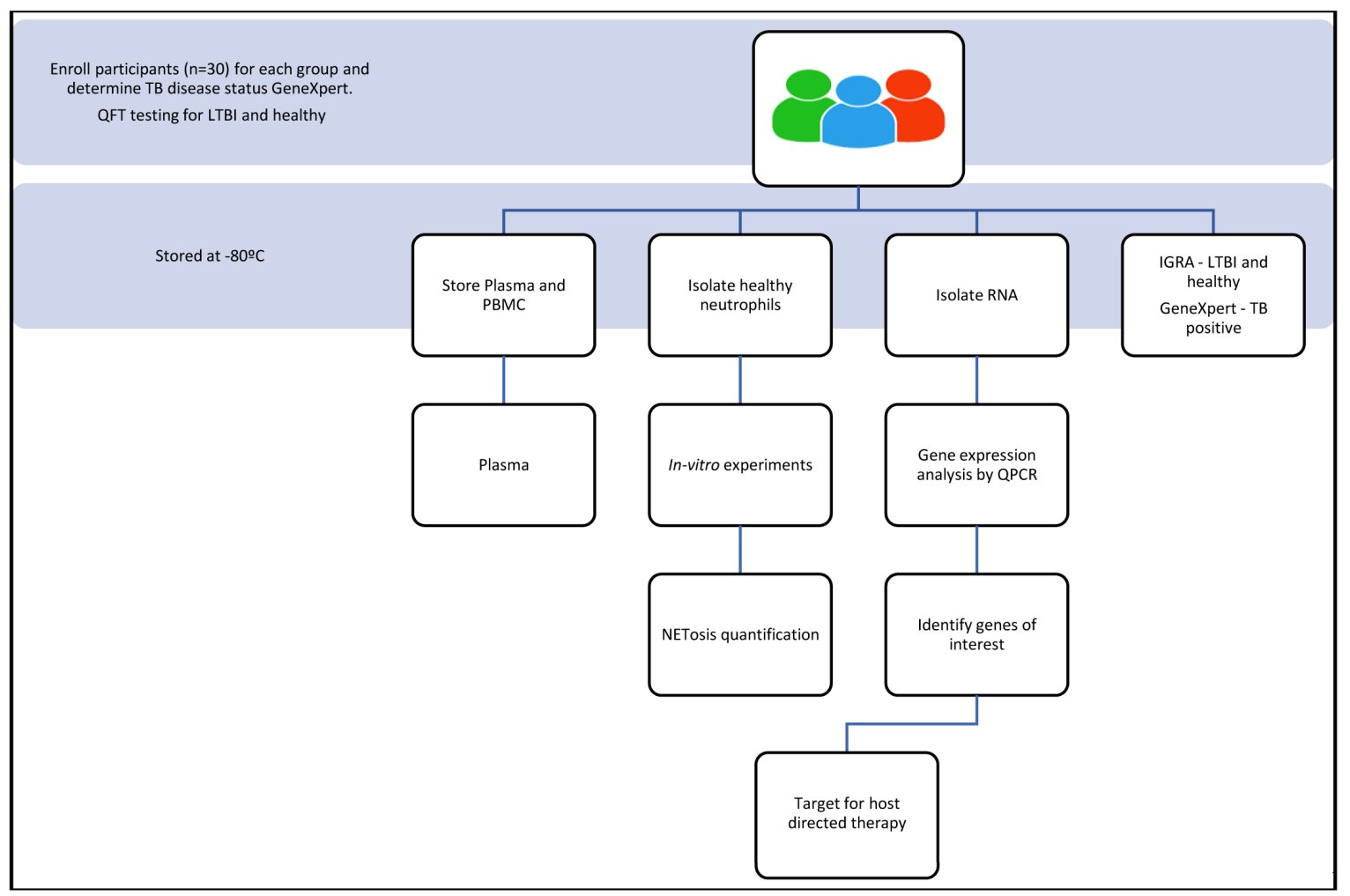

Figure 1. Schematic of the study design and experimental process that will be followed.

will be aspirated without disturbing the pellet. The pellet will be resuspended in $25 \mathrm{ml}$ of $0.01 \mathrm{M}$ of PBS and neutrophils counted using a hemocytometer.

\section{PBMC isolation}

To isolate PBMC from the blood, $10 \mathrm{ml}$ of blood will be added to twenty five millilitres of 0.01 M PBS (warmed to RT) (Sigma-Aldrich, USA). The diluted blood will then be layered onto fifteen millilitres of histopaque (warmed to RT) (Sigma-Aldrich, USA). A density gradient will be formed which will allow the cells to separate. The layered cells will be centrifuged at $800 \mathrm{x} \mathrm{g}$ for 30 minutes with the centrifuge setting of deceleration offand slow acceleration. Following centrifugation, the whitish layer (buffy layer) will be aspirated to a new $50 \mathrm{ml}$ tube and topped up with PBS and centrifuged at $300 \mathrm{x} \mathrm{g}$ for $10 \mathrm{~min}$, with acceleration and deceleration at maximum. The supernatant will be discarded, and the cells will be resuspended in PBS before being counted. The cells will be centrifuged at $300 \mathrm{x} \mathrm{g}$ for $10 \mathrm{~min}$ with maximum acceleration and deceleration. Freeze media will be prepared by adding 500 $\mu$ l of dimethyl sulfoxide (DMSO) (Sigma-Aldrich, USA) to four and half millilitres of fetal calf serum (FCS) (Sigma-Aldrich, USA). The supernatant will be removed, and the cells will be stored in $1 \mathrm{ml}$ of freeze media at a cell concentration of 10 million cells per $\mathrm{ml}$ in a cryovial labelled with the PID and date and stored in liquid nitrogen. Plasma will be isolated by transferring ten millilitres of blood to a tube, which will be centrifuged at $1000 \mathrm{x} \mathrm{g}$ for
10 minutes, with maximum acceleration and with deceleration off. Ten cryovials labelled with the PID and date, are used to store plasma at $-80^{\circ} \mathrm{C}$ at a volume of $500 \mu \mathrm{l}$.

\section{RNA extraction}

All surfaces and pipettes will be decontaminated with RNAse away before RNA isolation will be done. RNA will be extracted using the PAXgene kit and the corresponding protocol. Briefly, blood from TB, LTBI and healthy participants will be collected in PAXgene tubes that contain anticoagulant to ensure the stability of the ribonucleic acid (RNA). The blood will be stored at $18-25^{\circ} \mathrm{C}$ during transit and upon arrival will be stored at $-20^{\circ} \mathrm{C}$ at an angle on a wired rack for 24 hours before being transferred to the $-80^{\circ} \mathrm{C}$ freezer. The frozen blood in the PAXgene tubes will be thawed in a water bath at $22-23^{\circ} \mathrm{C}$ for 20 minutes and the PAXgene tube will be inverted 8-10 times to before RNA isolation proceeded. Once thawing and inverting of the tube is complete, the PAXgene tube is then left at room temperature (RT) for a further 2 hours to ensure complete cell lysis. RNA will be isolated from the blood using the PAXgene kit according to the manufacturer's instructions (PreAnalytiX, Hombrechtikon, Switzerland).

\section{RNA quality}

To determine the RNA quality, we will be using a Nanodrop Lite Spectrophotometer (Thermofisher TM, Switzerland) and the absorbance will be read at $260 \mathrm{~nm}$. The sample will be diluted (dilution factor 2) with $10 \mathrm{mM}$ of Tris-hydrochloride, $\mathrm{pH} 7.5$. 


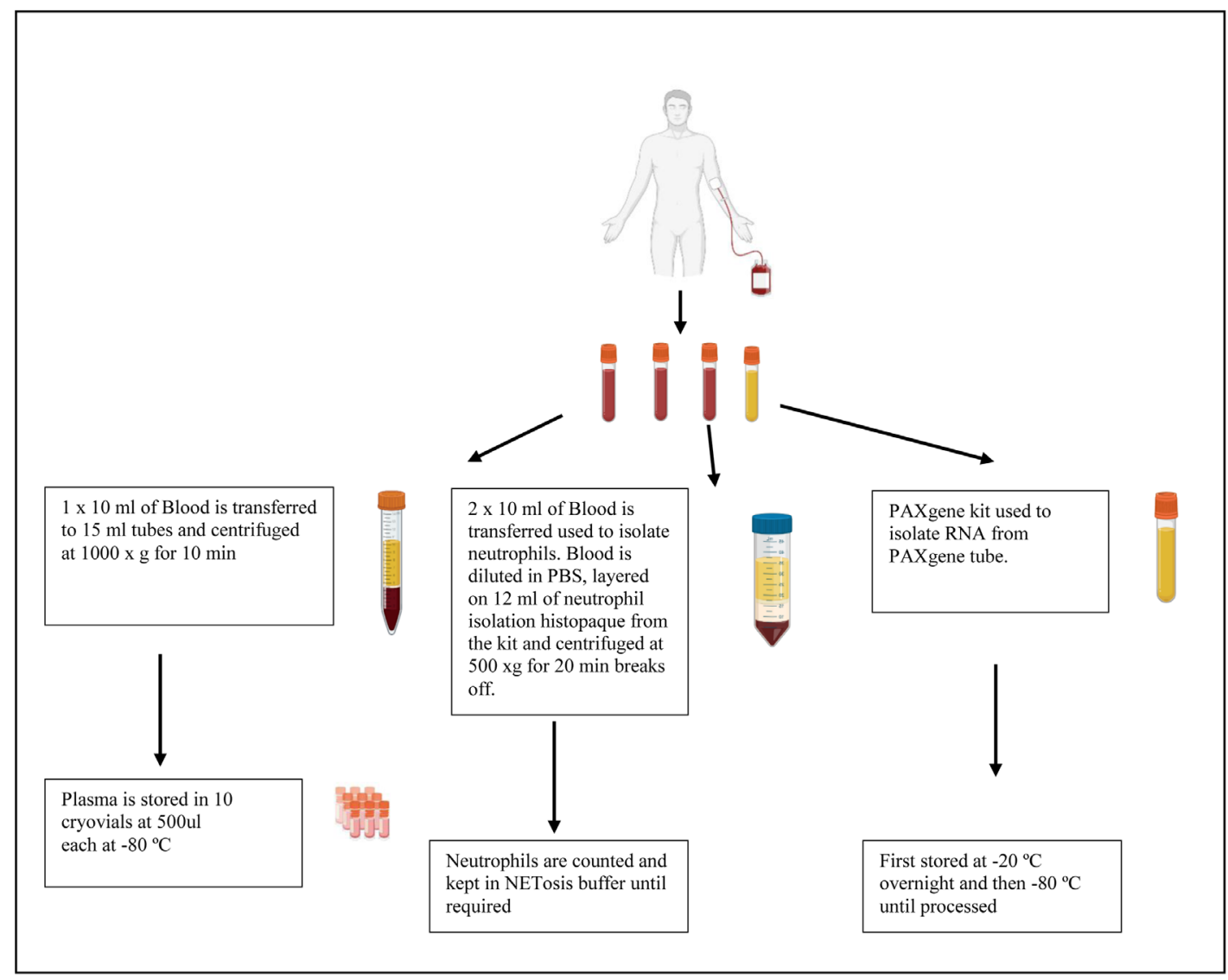

Figure 2. Schematic of plasma, neutrophil and RNA isolation from whole blood obtained from study participants.

The relationship between the absorbance and the RNA yield will be taken as A260 of 1 is equal to $44 \mathrm{ug} / \mathrm{ml}$, according to the manufacturer's instructions.

\section{cDNA synthesis}

The iScript cDNA synthesis kit will be used for cDNA synthesis as per manufacturer's instructions (Biorad, California, USA). The $5 \mathrm{x}$ iScript reaction mix will be left to thaw at room temperature. The reaction will be set-up in sterile PCR tubes as follows; $500 \mathrm{ng}$ of RNA will be added to each tube, followed by $4 \mu \mathrm{l}$ of $5 \mathrm{x}$ iScript reaction mix, $20 \mu \mathrm{l}$ of RNase free water and $1 \mu \mathrm{l}$ of iScript reverse transcriptase. The total reaction mix will be $20 \mu \mathrm{l}$ per tube. The tubes will be placed in a PCR machine and run on the thermocycler (Biorad, California, USA) using the following runs, $5 \mathrm{~min}$ at $25^{\circ} \mathrm{C}$, $30 \mathrm{~min}$ at $42^{\circ} \mathrm{C}, 5 \mathrm{~min}$ at $85^{\circ} \mathrm{C}$ and on hold at $4^{\circ} \mathrm{C}$. The resultant cDNA will be diluted $10 \mathrm{x}$ by adding $1 \mu \mathrm{l}$ of cDNA to $9 \mu \mathrm{l}$ of nuclease free water.

\section{RT-QPCR for gene expression}

Qualitative polymerase chain reaction (qPCR) will be done on candidate genes as per the manufacturer's instruction to determine the expression of the candidate genes in TB, LTBI and healthy participants. Briefly, half a microlitre of reverse primer, half a microlitre of the forward primer, three microlitres of nuclease free water and five microlitres of iTaq Universal SYBR green supermix (Biorad, California, USA) will be added to each well. A volume of nine microlitres of the mastermix will be added to each well. One microlitre of the diluted sample will be added to each well. The plate will be run on the Biorad CFX 96 thermocycler (Biorad, California, USA) according to the following protocol, $30 \mathrm{sec}$ at $95^{\circ} \mathrm{C}, 5 \mathrm{sec}$ at $95^{\circ} \mathrm{C}, 30 \mathrm{sec}$ at $59^{\circ} \mathrm{C}$, for 39 cycles. The melt curve analysis will be done at $65-95^{\circ} \mathrm{C}$ at $0.5^{\circ} \mathrm{C}$ increments.

\section{NETosis quantification}

A NETosis imaging kit (Cayman Chemical, Michigan, USA) will be used to quantify the amount of NETosis occurring in TB patients $(n=4)$ compared to healthy participants $(n=4)$. The assay will be performed as per manufacturer's instructions. Briefly, $6 \times 10^{6}$ neutrophils isolated on the same day, will be transferred to a clean tube and adjusted in 0.01M PBS to $1 \times 10^{6}$ cells $/ \mathrm{ml}$. a volume of six microlitres of Permeable Nuclear Red Reagent $(5 \mathrm{mM})$ will be added to each well and incubated in the dark at $37^{\circ} \mathrm{C}$ for $15-30$ minutes. A volume of $25 \mathrm{ml}$ of PBS will be added to the cells, centrifuged at $250 \mathrm{x} \mathrm{g}$ and the supernatant aspirated. The cells will be resuspended in twelve microlitres $\left(0.5 \times 10^{6}\right.$ cells $\left./ \mathrm{ml}\right)$ of 
NETosis Imaging buffer $(1 \mathrm{x})$. a volume of twelve microlitres of Extracellular Nuclear Green Reagent $(5 \mathrm{mM})$ will be added to the tube and mixed before the cells are seeded into the wells at $100 \mu \mathrm{l} /$ well in a flat-bottom 96 well plate (Greiner Costar, Sigma-Aldrich, Germany). A volume of $100 \mu \mathrm{l}$ of stimuli or NETosis Imaging Buffer $(1 \mathrm{x})$ will be added to each well for a final volume of $200 \mu \mathrm{l}$. The plate will be centrifuged at $250 \mathrm{x} \mathrm{g}$ to pellet the cells at the bottom of the plate. The BioTek cytation 5 (Biotek, Vermont, USA) which uses brightfield and fluorescence microscopy will be used to image activity every $30 \mathrm{~min}-1$ hour for six to twelve hours at a temperature of $37^{\circ} \mathrm{C}$ and $5 \% \quad \mathrm{CO}_{2}$. Green fluorescence indicates NETosis activity and red fluorescence is a marker for the nucleus (Figure 3). The neutrophils will be treated with optimized concentrations of various NETosis inhibitors depending on the chosen gene targets.

\section{Data analysis}

Student t-tests will be used to analyse the difference in gene expression between healthy, LTBI and TB participants. The data will be reported with the median and interquartile range. Pearson $\mathrm{R}$ Correlation or a Spearman $\mathrm{R}$ Correlation analysis will be done to determine if there is an association between protein and gene expression of specific NETosis associated protein and genes. All data will be analysed using Graphpad Prism v 9 software.

\section{Discussion}

Proteomic analysis of lung tissue laser microdissections of various granulomas showed that proteins associated with neutrophils were abundant in necrotic regions of caseous and cavitary granulomas ${ }^{16}$. This indicated that neutrophils potentially contribute to necrotic damage observed in cavitary granulomas, due to their presence in these regions. This provides a potential link of the neutrophils with increased TB pathogenesis, hence the need to investigate their role during $\mathrm{TB}$ as potential target for therapy or as biomarkers. Identifying factors or mechanisms that contribute to lung tissue damage is vital in identifying markers of disease progression.

Neutrophils have been identified in the regions that border necrotizing tissue in other diseases ${ }^{18}$ and how they contribute to caseation during $\mathrm{TB}$ infection remains poorly understood. Recent studies have also identified the role of DNA-MPO ${ }^{12,19}$ or histones complexes ${ }^{11,20}$, ROS pathways ${ }^{10}$ and neutrophil elastase $^{21}$ in tissue damage associated with various respiratory infections and as markers of disease progression. Studies in $\mathrm{C} 3 \mathrm{HeB} / \mathrm{FeJ}$ mice infected with Mtb have also shown that neutrophils contribute to necrosis and liquefaction of granulomas mediated by ROS events ${ }^{22}$. These studies suggest that similar mechanisms mediated by neutrophil derived proteins and cell death activities may be driving TB lung pathology in humans.

NETosis proteins have been detected in the serum of individuals with acute respiratory distress syndrome associated pathology ${ }^{23}$. However, whether NETosis directly contributes to damaging pathology observed in TB granulomas is not well known. To validate this, our initial aim is to establish whether NETosis associated genes are present in the blood and are differentially expressed in LTBI, TB and healthy participants. In addition, we aim to determine whether expression of specific genes associated with NETosis correlates with the spectrum of disease observed during TB infection (as reviewed by 24,25. In addition, these unique gene expression profiles may be used to identify potential biomarkers of disease progression that may be used to diagnose TB at point of care.
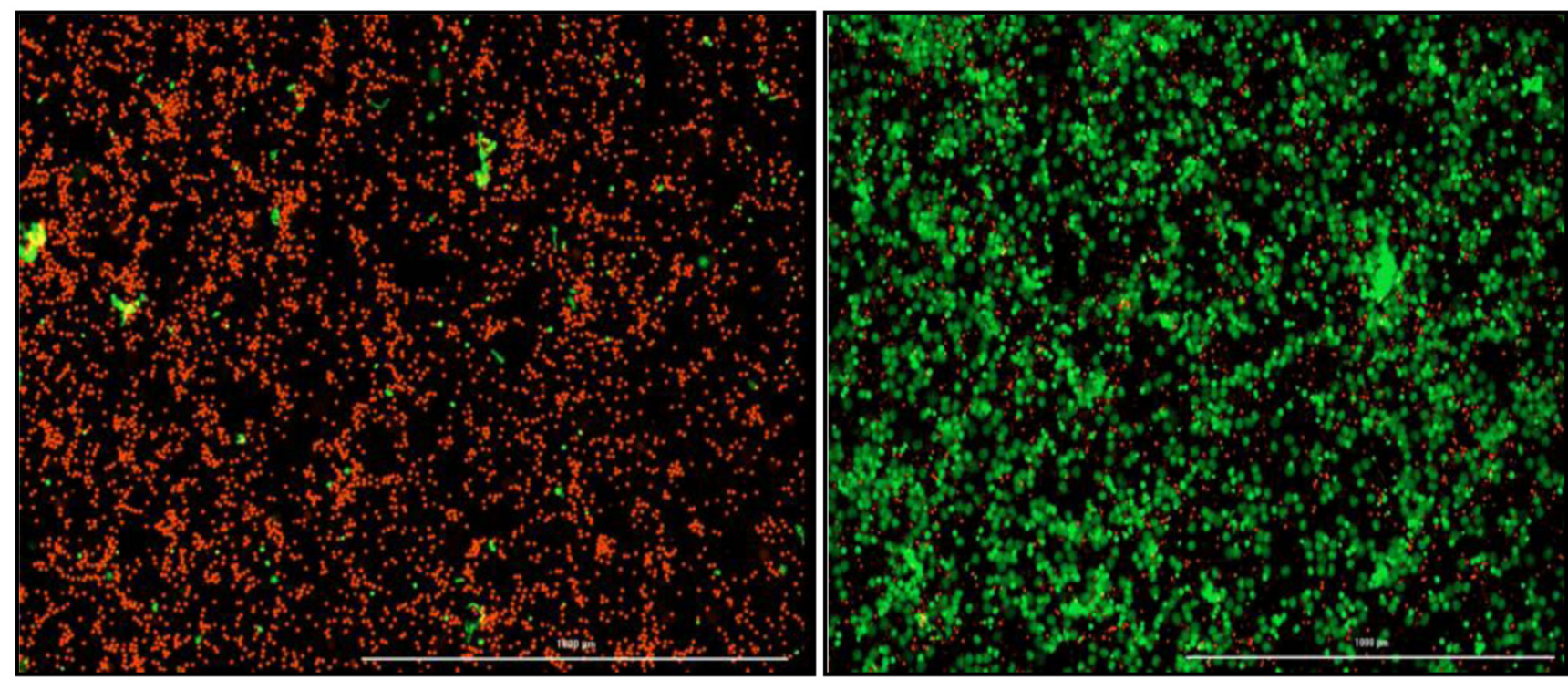

Figure 3. Images acquired with the Biotek Cytation $\mathbf{5}(\mathbf{1 0 0 0 \mu M )}$ to visualize and quantify NETosis. Red indicates intact neutrophils. Green indicates neutrophils undergoing NETosis and extruding their cellular DNA. (Left) Negative control which is only healthy neutrophils with no stimulation. (Right) Positive control, PMA stimulated neutrophils. 
Ongoing clinical trials are investigating the use of NETosis specific gene inhibitors to reduce tissue damage associated with NETotic events ${ }^{26-30}$. Therefore, identifying potential targets for HDTs that may serve as adjunct therapies to current antibiotic regimens remains vital in combating the disease.

Due to the heavy $\mathrm{TB}$ disease burden in $\mathrm{KZN}$, the study participants that will be enrolled in this study will provide important and relevant information regarding the tissue destruction mechanism that contributes to disease progression. A limitation of this study is that we will not be able to obtain matched blood samples from lung tissue donors. Another limitation of this study is that when performing the NETosis experiments it is difficult to distinguish between LTBI volunteers and those who are healthy in a timeous manner. This limits the ability of us to obtain a healthy blood volunteer to have an appropriate control.

The aim of this study is to identify potential biomarkers of TB disease progression that can lead to better diagnosis and ultimately, treatment of TB. We hope to characterize drivers of neutrophil mediated damage by developing a neutrophil in-vitro infection model. These findings may contribute to a better understanding of the neutrophil driven mechanisms that lead to damage often observed in the lungs of individuals with TB disease.

\section{Study status}

Recruitment of the study participants has been completed. The component of the study aimed to determine neutrophil related genes in healthy, LTBI and TB patients has been completed. The in vitro model of neutrophil Mtb infection has been optimized and detailed experiments on kinetics and mechanisms of TB induced of NETosis are ongoing.

\section{Data availability}

Data will be stored and available through the Africa Health Research Institute according to the Institute's protocols which ensure participant privacy and rights protection. Data generated will also be deposited into relevant public data repositories.

\section{Author contributions}

KLF and MJM wrote the manuscript. MJM conceived the study. KLF optimized the protocol and performed experiments. KRB, DM and KLF were responsible for developing and optimizing protocols for this study. TM provided helpful discussion in data analysis. DR assisted with instrumentation and imaging. MJM and TN supervised KLF and obtained funding for the study. All authors read and approved the manuscript in its current version.

\section{Acknowledgements}

We would like to thank all the study participants for their time and commitment to this study. We also thank the nurses and staff members and other personnel at clinical sites and all staff members at the clinical core at Africa Health Research Institute who helped with patient recruitment and sample processing.
1. World Health Organization: Global tuberculosis report 2020. 20th ed ed Geneva: World Health Organization; 2020. Reference Source

2. Davis JM, Ramakrishnan L. The role of the granuloma in expansion and dissemination of early tuberculous infection. Cell. 2009; 136(1): 37-49. PubMed Abstract | Publisher Full Text | Free Full Text

3. Ndlovu H, Marakalala MJ: Granulomas and Inflammation: Host-Directed Therapies for Tuberculosis. Front Immunol. 2016; 7: 434. PubMed Abstract | Publisher Full Text | Free Full Text

4. Mattila JT, Ojo OO, Kepka-Lenhart D, et al.: Microenvironments in tuberculous granulomas are delineated by distinct populations of macrophage subsets and expression of nitric oxide synthase and arginase isoforms. J Immunol. 2013; 191(2): 773-84.

PubMed Abstract | Publisher Full Text | Free Full Text

5. Eum SY, Kong JH, Hong MS, et al.: Neutrophils are the predominant infected phagocytic cells in the airways of patients with active pulmonary TB. Chest. 2010; 137(1): 122-8.

PubMed Abstract | Publisher Full Text | Free Full Text

6. Gideon HP, Phuah J, Junecko BA, et al.: Neutrophils express pro- and antiinflammatory cytokines in granulomas from Mycobacterium tuberculosisinfected cynomolgus macaques. Mucosal Immunol. 2019; 12(6): 1370-81. PubMed Abstract | Publisher Full Text | Free Full Text

7. Warnatsch A, Ioannou M, Wang Q, et al.: Inflammation. Neutrophil extracellular traps license macrophages for cytokine production in atherosclerosis. Science. 2015; 349(6245): 316-20. PubMed Abstract | Publisher Full Text | Free Full Text

8. Brinkmann V, Reichard U, Goosmann C, et al:: Neutrophil extracellular traps kill bacteria. Science. 2004; 303(5663): 1532-5. PubMed Abstract | Publisher Full Text
9. Branzk N, Lubojemska A, Hardison SE, et al.: Neutrophils sense microbe size and selectively release neutrophil extracellular traps in response to large pathogens. Nat Immunol. 2014; 15(11): 1017-25. PubMed Abstract | Publisher Full Text | Free Full Text

10. Martínez-Alemán S, Bustamante AE, Jimenez-Valdes RJ, et al.: Pseudomonas aeruginosa isolates from cystic fibrosis patients induce neutrophil extracellular traps with different morphologies that could correlate with their disease severity. Int J Med Microbiol. 2020; 310(7): 151451. PubMed Abstract | Publisher Full Text

11. Saffarzadeh M, Juenemann C, Queisser MA, et al:: Neutrophil extracellular traps directly induce epithelial and endothelial cell death: a predominant role of histones. PLoS One. 2012; 7(2): e32366. PubMed Abstract | Publisher Full Text | Free Full Text

12. Zhu L, Liu L, Zhang Y, et al:: High Level of Neutrophil Extracellular Traps Correlates With Poor Prognosis of Severe Influenza A Infection. J Infect Dis. 2018; 217(3): 428-37. PubMed Abstract | Publisher Full Text

13. Cowburn AS, Condliffe AM, Farahi N, et al.: Advances in neutrophil biology: clinical implications. Chest. 2008; 134(3): 606-12. PubMed Abstract | Publisher Full Text | Free Full Text

14. Shiratori B, Leano S, Nakajima C, et al.: Elevated OPN, IP-10, and neutrophilia in loop-mediated isothermal amplification confirmed tuberculosis patients. Mediators Inflamm. 2014; 2014: 513263. PubMed Abstract | Publisher Full Text | Free Full Text

15. Lowe DM, Redford PS, Wilkinson RJ, et al.: Neutrophils in tuberculosis: friend or foe? Trends Immunol. 2012; 33(1): 14-25. PubMed Abstract | Publisher Full Text

16. Marakalala MJ, Raju RM, Sharma K, et al.: Inflammatory signaling in human 
tuberculosis granulomas is spatially organized. Nat Med. 2016; 22(5): 531-8. PubMed Abstract | Publisher Full Text | Free Full Text

17. Kannabus A: TB Statistics South Africa. TBFACTS.org: 2021; [updated September 2021.

Reference Source

18. Bilyy R, Fedorov V, Vovk V, et al.: Neutrophil Extracellular Traps Form a Barrier between Necrotic and Viable Areas in Acute Abdominal Inflammation. Front Immunol. 2016; 7: 424.

PubMed Abstract | Publisher Full Text | Free Full Text

19. Kalil AC, Thomas PG: Influenza virus-related critical illness: pathophysiology and epidemiology. Crit Care. 2019; 23(1): 258.

PubMed Abstract | Publisher Full Text | Free Full Text

20. Toussaint $M$, Jackson DJ, Swieboda $D$, et al.: Host DNA released by NETosis promotes rhinovirus-induced type-2 allergic asthma exacerbation. Nat Med. 2017; 23(6): 681-91.

PubMed Abstract | Publisher Full Text | Free Full Text

21. Kirsebom F, Michalaki C, Agueda-Oyarzabal M, et al:: Neutrophils do not impact viral load or the peak of disease severity during RSV infection. Sci Rep. 2020; 10(1): 1110 PubMed Abstract | Publisher Full Text | Free Full Text

22. Marzo E, Vilaplana C, Tapia G, et al:: Damaging role of neutrophilic infiltration in a mouse model of progressive tuberculosis. Tuberculosis (Edinb). 2014; 94(1): 55-64.

PubMed Abstract | Publisher Full Text

23. Thompson BT, Chambers RC, Liu KD: Acute Respiratory Distress Syndrome. N Engl J Med. 2017; 377(6): 562-72.

PubMed Abstract | Publisher Full Text
24. Cadena AM, Fortune SM, Flynn JL: Heterogeneity in tuberculosis. Nat Rev Immunol. 2017; 17(11): 691-702.

PubMed Abstract | Publisher Full Text | Free Full Text

25. Pai M, Behr MA, Dowdy D, et al.: Tuberculosis. Nat Rev Dis Primers. 2016; 2: 16076.

PubMed Abstract | Publisher Full Text

26. Papayannopoulos V, Staab D, Zychlinsky A: Neutrophil elastase enhances sputum solubilization in cystic fibrosis patients receiving DNase therapy. PLoS One. 2011; 6(12): e28526.

PubMed Abstract | Publisher Full Text | Free Full Text

27. Lefrançais $\mathrm{E}$, Mallavia $\mathrm{B}$, Zhuo $\mathrm{H}$, et al.: Maladaptive role of neutrophil extracellular traps in pathogen-induced lung injury. JCI Insight. 2018; 3(3): e98178.

PubMed Abstract | Publisher Full Text | Free Full Text

28. Boone BA, Murthy P, Miller-Ocuin J, et al.: Chloroquine reduces hypercoagulability in pancreatic cancer through inhibition of neutrophil extracellular traps. BMC Cancer. 2018; 18(1): 678.

PubMed Abstract | Publisher Full Text | Free Full Text

29. Tagami T, Tosa R, Omura M, et al.: Effect of a selective neutrophil elastase inhibitor on mortality and ventilator-free days in patients with increased extravascular lung water: a post hoc analysis of the PiCCO Pulmonary Edema Study. J Intensive Care. 2014; 2(1): 67. PubMed Abstract | Publisher Full Text | Free Full Text

30. Stockley R, De Soyza A, Gunawardena K, et al.: Phase II study of a neutrophi elastase inhibitor (AZD9668) in patients with bronchiectasis. Respir Med. 2013; 107(4): 524-33.

PubMed Abstract | Publisher Full Text 


\section{Open Peer Review}

\section{Current Peer Review Status:}

\section{Version 1}

Reviewer Report 07 April 2022

https://doi.org/10.21956/gatesopenres.14730.r31865

(C) 2022 Goletti D. This is an open access peer review report distributed under the terms of the Creative Commons Attribution License, which permits unrestricted use, distribution, and reproduction in any medium, provided the original work is properly cited.

\section{Delia Goletti}

Translational Research Unit, National Institute for Infectious Diseases (INMI), Rome, Italy

This study is on a project that is going to be done on the evaluations of genes associated with neutrophil mediated cell death. The hypothesis is that their study might be useful as potential biomarkers of pathological damage and disease progression, as well as targets for host-directed therapy.

The hypothesis and protocol of the study are well written.

\section{Few comments}

\section{Methods:}

Please comment on how the number of patients and controls was chosen.

Please comment on the definition of patients with latent tuberculosis infection, and which tests/radiological tools you will use to define them

Please comment on the definition of patients' active tuberculosis, and which tests/radiological tools you will use to define them

Is the rationale for, and objectives of, the study clearly described?

Yes

Is the study design appropriate for the research question?

Yes

Are sufficient details of the methods provided to allow replication by others? Yes

Are the datasets clearly presented in a useable and accessible format? 
Yes

Competing Interests: No competing interests were disclosed.

Reviewer Expertise: Immunology of tuberculosis and COVID-19 and Echinococcosis.

I confirm that I have read this submission and believe that I have an appropriate level of expertise to confirm that it is of an acceptable scientific standard.

Author Response 25 Apr 2022

Mohlopheni Jackson Marakalala, Africa Health Research Institute, Durban, South Africa

\section{Reviewer 2}

Please comment on how the number of patients and controls was chosen.

Please comment on the definition of patients with latent tuberculosis infection, and which tests/radiological tools you will use to define them

Please comment on the definition of patients' active tuberculosis, and which tests/radiological tools you will use to define them

Response to reviewer 2:

We appreciate the useful comments by Reviewer 2 which we believe will help strengthen our manuscript.

We will not be using a radiological test to confirm TB infection but rather GeneXpert. Those individuals who are GeneXpert positive will be recruited to the TB group. Those individuals who will be recruited to the healthy group were further tested to determine whether they were perhaps latently infected with TB using the quantiferon (QFT) test. Those that have a positive QFT result will be recruited to the LTBI group $(n=30)$ and those that have a negative QFT result will be recruited to the healthy group $(n=30)$.

Please see below edits to the manuscript on lines 86-91:

"Individuals who are newly diagnosed with active $T B$, determined as GeneXpert positive and who have not received treatment, will be recruited to the TB group of the study $(n=30)$. Individuals who are healthy will be recruited to the healthy group as determined by their quantiferon (QFT) results. If the QFT result is positive those individuals will be recruited to the LTBI group $(n=30)$ and those who are QFT negative will be recruited to the healthy group $(n=30) . "$

The size of the group was determined based on our discovery proteomics data. We decided to investigate the neutrophil specific protein responses in a small cohort that would allow us to determine if similar responses were seen in local populations within KZN. We acknowledge that the sample size is small and is a limitation of this study. However, the findings of this study could be validated in a larger cohort, should promising biomarkers of disease progression be discovered. 
Competing Interests: No competing interests to disclose

Reviewer Report 02 February 2022

https://doi.org/10.21956/gatesopenres.14730.r31616

(C) 2022 Kumar A. This is an open access peer review report distributed under the terms of the Creative Commons Attribution License, which permits unrestricted use, distribution, and reproduction in any medium, provided the original work is properly cited.

\section{Ashwani Kumar}

Council of Scientific and Industrial Research, Institute of Microbial Technology, Chandigarh, Chandigarh, Punjab and Haryana, India

Study protocol titled "Investigating neutrophil cell death in TB pathogenesis" provides details of methods related to the assessment of differential gene expression in PBMCs and their association with latency of TB (if any). It also provides details of methods that could assist in deciphering genes involved in NETosis. Overall the manuscript is well written and provides sufficient details of methods. I would like to suggest a few minor changes to the manuscript.

1. Study size and ethics sub-headings of the Methods section shall provide sample size, expected numbers of individuals that will be enrolled in the study and its justification.

2. Background section, line 1, authors could use a recent TB report 2021 instead of Global TB report 2020.

3. There are a few grammatical errors in the methods sections, correcting these may improve the readability of the manuscript. As an example in the "study size and ethics" sub-heading, "plasma is collected' is used. It could be changed to "plasma will be collected".

4. Authors should use the convention of a space between numbers and units eg., " $5 \mathrm{mM}$ " instead of " $5 \mathrm{mM}$ ".

Is the rationale for, and objectives of, the study clearly described?

Yes

Is the study design appropriate for the research question?

Yes

Are sufficient details of the methods provided to allow replication by others?

Yes

Are the datasets clearly presented in a useable and accessible format?

Yes 
Competing Interests: No competing interests were disclosed.

Reviewer Expertise: TB Pathogenesis

I confirm that I have read this submission and believe that I have an appropriate level of expertise to confirm that it is of an acceptable scientific standard.

Author Response 25 Apr 2022

Mohlopheni Jackson Marakalala, Africa Health Research Institute, Durban, South Africa

We appreciate the useful comments by Reviewer 1 which we believe will help strengthen our manuscripts.

Reviewer 1

1. Study size and ethics sub-headings of the Methods section shall provide sample size, expected numbers of individuals that will be enrolled in the study and its justification.

Response to question 1:

Please see below edits to the manuscript on line 86-91:

"Individuals who are newly diagnosed with active TB and are GeneXpert positive, will be recruited to the TB group of the study $(n=30)$. Individuals who are healthy will be recruited to the healthy group as determined by their quantiferon (QFT) results. If the QFT result is positive those individuals will be recruited to the LTBI group $(n=20)$ and those who are QFT negative will be recruited to the healthy group $(n=20) . "$

2. Background section, line 1, authors could use a recent TB report 2021 instead of Global TB report 2020.

A more recent TB report has been used. Please see line 39 and 380.

3. There are a few grammatical errors in the methods sections, correcting these may improve the readability of the manuscript. As an example in the "study size and ethics" sub-heading, "plasma is collected" is used. It could be changed to "plasma will be collected".

The manuscript has been edited to change the tense to the correct grammatical tense.

4. Authors should use the convention of a space between numbers and units eg., "5 $\mathrm{mM}$ " instead of " $5 \mathrm{mM}$ "

The manuscript has been edited to include a space between the number and units of measurements. 
Competing Interests: No competing interests to disclose 